\title{
Clinical Study \\ Effects of Walking Endurance Reduction on Gait Stability in Patients with Stroke
}

\author{
M. Iosa, ${ }^{1}$ G. Morone, ${ }^{1}$ A. Fusco, ${ }^{1}$ L. Pratesi, ${ }^{2}$ M. Bragoni, ${ }^{2}$ P. Coiro, ${ }^{2}$ M. Multari, ${ }^{2}$ \\ V. Venturiero, ${ }^{2}$ D. De Angelis, ${ }^{2}$ and S. Paolucci ${ }^{1,2}$ \\ ${ }^{1}$ Clinical Laboratory of Experimental Neurorehabilitation, Santa Lucia Foundation I.R.C.C.S., via Ardeatina 306, 00179 Rome, Italy \\ ${ }^{2}$ Operative Unit F, Santa Lucia Foundation I.R.C.C.S., via Ardeatina 306, 00179 Rome, Italy
}

Correspondence should be addressed to M. Iosa, m.iosa@hsantalucia.it

Received 6 June 2011; Revised 18 July 2011; Accepted 19 July 2011

Academic Editor: Julie A. Bernhardt

Copyright (c) 2012 M. Iosa et al. This is an open access article distributed under the Creative Commons Attribution License, which permits unrestricted use, distribution, and reproduction in any medium, provided the original work is properly cited.

\begin{abstract}
Control of gait is usually altered following stroke, and it may be further compromised by overexertion and fatigue. This study aims to quantitatively assess patients' gait stability during six-minute walking, measuring upper body accelerations of twenty patients with stroke $(64 \pm 13$ years old) and ten age-matched healthy subjects ( $63 \pm 10$ years old). Healthy subjects showed a steady gait in terms of speed and accelerations over the six minutes. Conversely, the patients unable to complete the test $(n=8)$ progressively reduced their walking speed $\left(-22 \pm 11 \%\right.$, confidence interval $\left.\mathrm{CI}_{95 \%}:-13,-29 \%, P=0.046\right)$. Patients able to complete the test $(n=12)$ did not vary their walking speed over time $(P=0.493)$. However, this ability was not supported by an adequate capacity to maintain their gait stability, as shown by a progressive increase of their upper body accelerations $\left(+5 \pm 11 \%, \mathrm{CI}_{95 \%}\right.$ : -1 ; $+12 \%, P=0.010)$. Walking endurance and gait stability should be both quantitatively assessed and carefully improved during the rehabilitation of patients with stroke.
\end{abstract}

\section{Introduction}

The recovery of walking ability is one of the most relevant functional targets after a cerebrovascular event, but this goal is generally obtained by only $50-60 \%$ of patients [1]. In particular, Paolucci and colleagues showed that at discharge from a rehabilitation hospital about $5 \%$ of patients with stroke were independent even in stair climbing and $9 \%$ were able to walk outside, $14 \%$ to walk inside, and $27 \%$ to walk with cane or other aid, while $45 \%$ remained in wheelchair [2].

Prolonged walking in living environment is even more challenging than short distances walked in hospital settings. Furthermore, overexertion can be detrimental for physical and mental conditions of people with stroke: for these patients, fatigue prevalence has been estimated to be up to $70 \%[3,4]$. Fatigue can be defined as a feeling of lack of energy and weariness following a period of exertion, and it is characterized by a decreased capacity of work and reduced efficiency to respond to stimuli [5]. All these factors put the individuals with stroke at great risk of falling during prolonged walking [6]. Despite that the effects of fatigue, induced by extended effortful activity, have been investigated in relationship to spatiotemporal gait parameters $[7,8]$ and oxygen consumption [5] in people with stroke, far too little attention has been paid to the relationship between walking endurance and gait stability.

Gait dynamic stability could be defined as the capacity to move the body segments in a coordinated fashion so that the body could be displaced with a proper speed (i.e., functional to the required task, such as crossing the road safely) minimizing upper body oscillations $[9,10]$. So, gait stability can be suitably assessed by measuring upper body accelerations [9], in terms of their dispersion and smoothness of upper body walking patterns [10-12]. In fact, in an unstable gait, walking speed fluctuates, causing higher accelerations and hence inertial forces and perturbations that need to be controlled.

The aim of this study is to quantify the potential effects of fatigue, induced by effortful walking, on gait dynamic stability of patients with stroke. The hypothesis that we wanted to test was if gait stability is reduced during prolonged walking 
in people with subacute stroke. To achieve this goal, we have measured upper body accelerations during the six-minute walking test performed by ambulatory inpatients.

\section{Material and Methods}

2.1. Participants. Twenty patients with stroke and ten agematched healthy subjects were enrolled in this study (see Table 1 reporting their demographic and clinical characteristics). The patients were tested the day before their dismissal from a rehabilitation hospital. Exclusion criteria were inability to walk, severe cognitive impairment, medical contraindications to exercise training, other chronic disabling pathologies (such as osteoarthritis and chronic inflammatory rheumatic diseases), orthopedic injuries, and hemispatial neglect. This study was approved by the Local Ethical Committee, and informed consent was obtained from each participant.

2.2. Clinical Assessment. To assess the independency in activities of daily living and the walking ability of our patients, we administered them the Barthel Index (BI) and the Functional Ambulation Classification (FAC), respectively. BI is one of the best known and commonly used scales to assess the degree of independence a patient demonstrates in various activities of daily living, including mobility and transfers (in particular, bowel and bladder function, grooming, toilet use, feeding, transfers, mobility, dressing, climbing stairs, and bathing). Its total score ranges from 0 (total dependence) to 100 (total independence) [13]. FAC is a six-point hierarchical rating scale that reflects the amount of assistance a person requires to walk. This scale allows to easily classify patients in respect of their walking ability, with maximum score identifying a person able to ambulate independently on nonlevel surfaces [14]. The median values (first, third quartiles) of these scales are reported in Table 1.

2.3. Walking Endurance Assessment. The six-minute walking test (6MWT) was used to measure walking endurance, as usually done in clinical settings $[6,8,15,16]$. Participants were asked to cover the maximum distance in six minutes self-selecting their speed to do it. They were instructed that they could slow down and rest if necessary and then start again to walk. Patients were allowed to use a cane or a walker and/or to perform the test under physiotherapist supervision, if needed (slight contact might have been required at times). All the participants (patients and healthy subjects) were asked to walk with their common shoes for 6 minutes along a $20 \mathrm{~m}$ level walkway, from one extreme to another, in the rehabilitation gym of our hospital. They were told about the lasting time at the third and fifth minute of walking [8]. At the end of test, the walked distance was measured. This distance and the distances walked at the end of each one of the six minutes were evaluated using tape strips fixed on the ground every $2.5 \mathrm{~m}$ of the walkway. Patients able to walk for 6 minutes were grouped in PG1, whereas patients unable to complete the test were grouped in PG2.

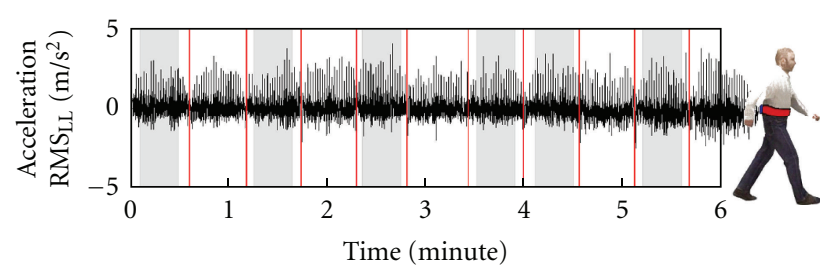

FIGURE 1: The acceleration signal along laterolateral direction of a patient. The grey large bands highlight the analysed part of the signal for each one of the 6 minutes of the test. The thin red lines indicate the end of each $20 \mathrm{~m}$ lap.

2.4. Gait Stability Assessment. During the 6MWT, the participants wore an elastic belt including a light wearable inertial sensor device (FreeSense, Sensorize s.r.l., Rome; sampling frequency $=100 \mathrm{~Hz}$, weight $=93 \mathrm{~g}$ ) located on their back in correspondence of L2-L3 spinous processes, close to their body centre of mass. This device contains a triaxial accelerometer to separately measure three accelerations, each one along one of the three body axes (anteroposterior AP, laterolateral LL, and craniocaudal CC).

Accelerometer signals were $20 \mathrm{~Hz}$ low-pass filtered, transformed to give a mean equal to zero, and summarized in their root mean square (RMS) [10-12]. RMS is a measure of acceleration dispersion and therefore of the smoothness of movement patterns. This makes RMS the parameter most commonly used to assess gait stability by means of accelerometry [9].

For each one of the six minutes of walking, the mean walking speed was computed as the meters walked in that minute divided into $60 \mathrm{~s}$, and the mean RMS was computed on the accelerometric signals recorded in a central part of the linear walking performed in that minute (see Figure 1). Conversely, accelerometric data recorded during the two turning parts of the walkway were not analysed.

2.5. Statistical Analysis. Mean \pm standard deviation and 95\% confidence interval $\left(\mathrm{CI}_{95 \%}\right)$ have been computed for continuous measures and median and 1st and 3rd quartiles for scale scores. Analogously, $t$-test was used for comparisons between two continuous measures (age, days, height, and body mass index), Mann-Whitney $u$ test for scale scores (BI and FAC), and $\chi^{2}$ test for binary variables (gender, side of hemiparesis, and types of stroke). The differences between walking speeds recorded at the 1 st minute and the 6 th minute for each subgroup of participants were assessed by means of paired $t$-tests.

An analysis of variance (ANOVA) was performed in order to compare the values of walked distance and walking speeds among the three groups (between subjects factor), followed by post hoc comparison performed with Tukey's test (see Table 2).

A repeated measure ANOVA was performed on the RMS values of participants able to complete the test (PG1 and $\mathrm{CG}$ ) to assess the changes over time (within-factor: 1, 2, 3, 4, 5, and 6 minutes) and the effects of group (between-factor: PG1, CG) and body axis (between-factor: AP, LL, and CC). Conversely, for PG2, in which not all subjects walked for 
TABle 1: Demographic and clinical characteristics of participants. Mean \pm standard deviation (95\% confidence interval) or median (first and third quartiles) of demographic characteristics, clinical features and scale scores at the moment of the 6MWT. The fourth and the last columns report the $P$ values obtained by $t$ test for continuous measures, Mann-Whitney $u$ test for BI and FAC, and $\chi^{2}$ test for side of hemiparesis and types of stroke.

\begin{tabular}{|c|c|c|c|c|c|c|}
\hline Characteristics & $\begin{array}{c}\text { CG } \\
(n=10)\end{array}$ & $\begin{array}{c}\text { PG } \\
(n=20)\end{array}$ & $\begin{array}{c}P \\
\text { CG versus PG }\end{array}$ & $\begin{array}{c}\text { PG1 } \\
(n=12)\end{array}$ & $\begin{array}{c}\text { PG2 } \\
(n=8)\end{array}$ & $\begin{array}{c}P \\
\text { PG1 versus PG2 }\end{array}$ \\
\hline Age (years old) & $\begin{array}{l}62.8 \pm 9.7 \\
(56.8 ; 68.8)\end{array}$ & $\begin{array}{l}64.4 \pm 13.0 \\
(58.7 ; 70.1)\end{array}$ & 0.734 & $\begin{array}{l}62.7 \pm 14.7 \\
(54.4 ; 70.1)\end{array}$ & $\begin{array}{l}67.0 \pm 10.0 \\
(59.8 ; 74.2)\end{array}$ & 0.468 \\
\hline Height (m) & $\begin{array}{l}1.68 \pm 0.10 \\
(1.61 ; 1.74)\end{array}$ & $\begin{array}{l}1.69 \pm 0.11 \\
(1.64 ; 1.74)\end{array}$ & 0.795 & $\begin{array}{l}1.69 \pm 0.13 \\
(1.62 ; 1.76)\end{array}$ & $\begin{array}{l}1.69 \pm 0.09 \\
(1.63 ; 1.75)\end{array}$ & 0.975 \\
\hline $\begin{array}{l}\text { Body mass Index } \\
\left(\mathrm{kg} / \mathrm{m}^{2}\right)\end{array}$ & $\begin{array}{l}25.5 \pm 2.4 \\
(24.0 ; 27.0)\end{array}$ & $\begin{array}{c}26.29 \pm 4.17 \\
(24.5 ; 28.1)\end{array}$ & 0.594 & $\begin{array}{c}26.86 \pm 4.33 \\
(24.4 ; 29.3)\end{array}$ & $\begin{array}{c}25.43 \pm 4.04 \\
(22.6 ; 28.2)\end{array}$ & 0.469 \\
\hline Women & 5 & 6 & \multirow{2}{*}{0.284} & 4 & 2 & \multirow{2}{*}{0.690} \\
\hline Men & 5 & 14 & & 8 & 6 & \\
\hline $\begin{array}{l}\text { Time from the event } \\
\text { (days) }\end{array}$ & - & $\begin{array}{c}132 \pm 103 \\
(86.9 ; 177.1)\end{array}$ & - & $\begin{array}{c}101 \pm 36 \\
(80.6 ; 121.4)\end{array}$ & $\begin{array}{c}180 \pm 149 \\
(76.7 ; 283.3)\end{array}$ & 0.091 \\
\hline Length of stay (days) & - & $\begin{array}{c}92 \pm 41 \\
(74.0 ; 110.0)\end{array}$ & - & $\begin{array}{c}83 \pm 32 \\
(64.9 ; 101.1)\end{array}$ & $\begin{array}{c}104 \pm 51 \\
(68.7 ; 139.3)\end{array}$ & 0.277 \\
\hline Barthel index & - & $\begin{array}{c}60 \\
(44 ; 88)\end{array}$ & - & $\begin{array}{c}70 \\
(50 ; 88)\end{array}$ & $\begin{array}{c}46 \\
(38 ; 73)\end{array}$ & 0.341 \\
\hline $\begin{array}{l}\text { Functional } \\
\text { Ambulation } \\
\text { Classification }\end{array}$ & 一 & $\begin{array}{c}4 \\
(2 ; 5)\end{array}$ & - & $\begin{array}{c}4 \\
(3 ; 5)\end{array}$ & $\begin{array}{c}3 \\
(2 ; 4)\end{array}$ & 0.327 \\
\hline Right & - & 12 & - & 7 & 5 & 0.852 \\
\hline Left hemiparesis & & 8 & & 5 & 3 & \\
\hline Ischemic & - & 18 & - & 11 & 7 & 0.761 \\
\hline haemorrhagic & & 2 & & 1 & 1 & 0.701 \\
\hline
\end{tabular}

the same time, paired $t$-test was performed to compare the RMS values recorded at the 1st and at the last minute of their test. The linear fit and relevant determination coefficient $\left(R^{2}\right)$ were computed for assessing the relationship between RMSs and time. For all the tests, the significance level was set at 0.05 .

\section{Results}

3.1. Clinical Tests, Gait Speed, and Walking Endurance. Twelve of the twenty patients were able to complete the 6MWT (subgroup PG1) and eight patients asked to definitively stop the test before its planned conclusion (PG2). The clinical characteristics of PG1 and PG2 are summarized in Table 1. No significant clinical differences were found between these two groups, although the clinical picture of PG2 was quite worse (older, lower BI and FAC scores).

In terms of gait performance, a significant difference was observed in terms of walked distance among the three groups (Table 2). Healthy subjects covered a significantly longer distance than that covered by PG1 $(P<0.001)$ and PG2 $(P<0.001)$, and PG1 walked significantly more than PG2 $(P=0.007)$. On the other hand, the mean walking speed, computed over the entire test, was not statistically different between the two groups of patients (but both lower than that of CG, $P<0.001$ ). This may be explained by the fact that the higher distance covered by PG1 in respect of PG2 was mainly due to the longer time spent walking ( $360 \mathrm{~s}$ for PG1 versus
$245 \pm 67$ s for PG2). However, the walking speed recorded in the last minute of the test was significantly lower in PG2 than in PG1 (see Table 2). It was due to a speed reduction observed in all the subjects of PG2 between the first and the last minutes of walking (mean: $-22 \pm 11 \% ; P=0.046$, paired $t$-test). The same analysis performed on PG1 $(+1 \pm 11 \%$, $P=0.493)$ and CG $(-1 \pm 7 \%, P=0.537)$ did not show any significant change in terms of walking speed over the course of the test.

3.2. Gait Stability Assessment. Despite the reduction of walking speed observed in PG2, their acceleration RMSs were not reduced between the first and the last minutes of the test $(P>0.05$ for all the three RMSs measured along the three body axes). Conversely, 8 out of 12 patients able to complete the test showed an increase of accelerations at least along 2 body axes between the 1st and the 6th minutes of the test. It resulted in a mean progressive increment of all the RMS values of PG1 (about $+5 \%$, significant for $\mathrm{RMS}_{L L}:+7 \pm 11 \%$, $P=0.048$ ), not observed in CG (about $-1 \%$ ). Figure 2 clearly shows this mean increment of acceleration in PG1; however 5 out of these 12 patients showed a reduction of their walking speed during the last minute of the test. A repeated measure ANOVA performed on all the participants who walked for all the 6 minutes (PG1 and CG) showed that the interaction between time and group significantly affected the RMS values $(F=3.082, P=0.010)$, whereas neither the main factor time $(F=1.981, P=0.081)$ nor its interaction with body axis has 
TABLE 2: Gait parameters. Mean \pm standard deviation $\left(\mathrm{CI}_{95 \%}\right)$ of gait parameters recorded during $6 \mathrm{MWT}$ for the three groups of participants. The last two columns reported the statistical analyses. For PG2, the last minute walking speed was the minute before stopping.

\begin{tabular}{|c|c|c|c|c|c|}
\hline \multirow[b]{2}{*}{ Gait parameters } & \multirow{2}{*}{$\begin{array}{c}\text { PG1 } \\
(n=12)\end{array}$} & \multirow{2}{*}{$\begin{array}{c}\text { PG2 } \\
(n=8)\end{array}$} & \multirow{2}{*}{$\begin{array}{c}\text { CG } \\
(n=10)\end{array}$} & \multicolumn{2}{|c|}{ Analysis } \\
\hline & & & & $\begin{array}{c}\text { ANOVA } \\
\text { PG1, PG2, CG }\end{array}$ & $\begin{array}{c}\text { Post-hoc } \\
\text { PG1 versus PG2 }\end{array}$ \\
\hline \multirow{2}{*}{ Walked distance (m) } & $226 \pm 111$ & $94 \pm 73$ & $413 \pm 57$ & $F=31.03$ & \multirow{2}{*}{$P=0.007$} \\
\hline & $(163 ; 289)$ & $(43 ; 144)$ & $(378 ; 448)$ & $P<0.001$ & \\
\hline \multirow{2}{*}{ Walking speed $(\mathrm{m} / \mathrm{s})$} & $0.63 \pm 0.31$ & $0.37 \pm 0.25$ & $1.15 \pm 0.16$ & $F=22.72$ & \multirow{2}{*}{$P=0.082$} \\
\hline & $(0.45 ; 0.81)$ & $(0.20 ; 0.54)$ & $(1.04 ; 1.26)$ & $P<0.001$ & \\
\hline 1st minute & $0.62 \pm 0.30$ & $0.43 \pm 0.30$ & $1.17 \pm 0.18$ & $F=19.69$ & \multirow{2}{*}{$P=0.271$} \\
\hline Walking speed $(\mathrm{m} / \mathrm{s})$ & $(0.45 ; 0.79)$ & $(0.22 ; 0.64)$ & $(1.05 ; 1.29)$ & $P<0.001$ & \\
\hline last minute & $0.64 \pm 0.32$ & $0.32 \pm 0.18$ & $1.16 \pm 0.13$ & $F=28.29$ & \multirow{2}{*}{$P=0.019$} \\
\hline Walking speed $(\mathrm{m} / \mathrm{s})$ & $(0.46 ; 0.82)$ & $(0.20 ; 0.44)$ & $(1.07 ; 1.25)$ & $P<0.001$ & \\
\hline
\end{tabular}

a significant effect on the acceleration $\mathrm{RMSs}(F=1.810, P=$ $0.058)$.

\section{Discussion}

In this study, we observed a progressive reduction of gait dynamic stability in patients with stroke during prolonged walking. To test the relationship between walking endurance and gait stability, we compared the performances of inpatients with those of an age- and height-matched group of healthy subjects, combining the 6-minute walking test with the measure of upper body accelerations.

As expected, the walked distance at the end of the test and the mean walking speed were both lower in patients than in healthy subjects. The lower walking speed of patients implied lower accelerations, facilitating their control of upper body stability $[9,11]$. In this study, the need of RMS normalization to compare populations walking at different speeds [12] has been avoided by analyzing the within-subject variations of RMS values along the test.

During the six minutes of the test, neither walking speed nor trunk accelerations significantly varied for control subjects. Conversely, patients showed a progressive reduction of their walking speed and/or gait stability.

In healthy subjects, it was already found that a reduced gait velocity results in a corresponding reduction of acceleration amplitudes [9]. However, this association between velocity and acceleration was found altered in our patients during the 6MWT. In fact, despite the systematic speed reduction observed in PG2, their trunk accelerations were not reduced during the test. On the other hand, this association resulted reduced also in patients able to complete the test (PG1). In fact, they were able to maintain their self-selected walking speed over the entire test, but many of them also showed a progressive increment of upper body accelerations. The speed reduction observed in PG2 without any acceleration decrease and the increase of upper body accelerations mainly observed in PG1 keeping constant their walking speed indicate that the patients' walking endurance and gait stability were challenged during this test [17].
Our results suggest that patients used two possible alternative strategies to perform the 6MWT. Some of them were able to keep their speed quite constant during walking, despite a slight but progressive reduction of their upper body stability. These subjects were mainly those of PG1, that is, the group able to complete the test. Other subjects seemed to apply a compensation strategy based on the reduction of their walking speed. It probably facilitated the management of their progressive reduction of gait stability during this effortful walking task. As stated above, the reduction of walking speed is, in fact, a suitable strategy for reducing upper body accelerations $[9,11]$. This last strategy has been observed especially in those patients who asked to stop the test before its planned conclusion.

In previous studies, for patients with chronic stroke performing the 6MWT, neither differences in velocities for each 1-minute interval [18] nor differences in energy consumption [5] were found significant over the course of the walk. The effects of fatigue were probably not highlighted by these measures [18]. Conversely, changes in gait symmetry [7] and in unaffected lower limb extensor power [5] were found associated with fatigue mechanisms over some minutes of walking.

However, far too little attention has been paid to the reduction of gait stability during prolonged walking, which may potentially increase the risk of falls [9]. In fact, the correlations between upper body accelerations and fall risk have been proven [19]. Falls are one of the most important problems among people after stroke, implying physical and psychological consequences associated with restricted activity as a result of fractures [20] and fear of new falls [21]. During level walking, the main causes of falling are quick walking speed in respect of the actual patient's locomotor capacity, anterior body mass carriage, and step timing delays $[22,23]$. In daily living environment, it is conceivable that the patients who self-selected to keep constant their walking speed in spite of an increase of their upper body instabilities may be exposed to a high risk of fall.

In fact, in this study, we found an increment of patients' upper body accelerations, especially along anteroposterior and laterolateral directions over six-minute walking. These 


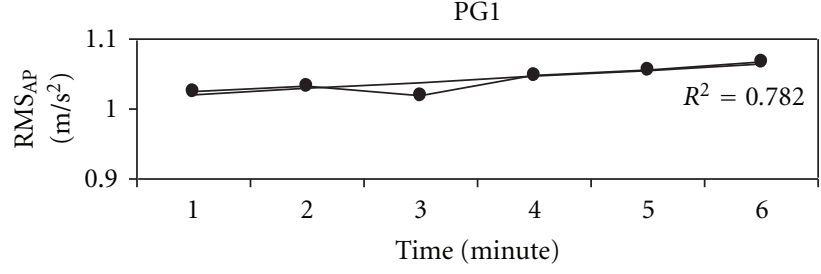

(a)

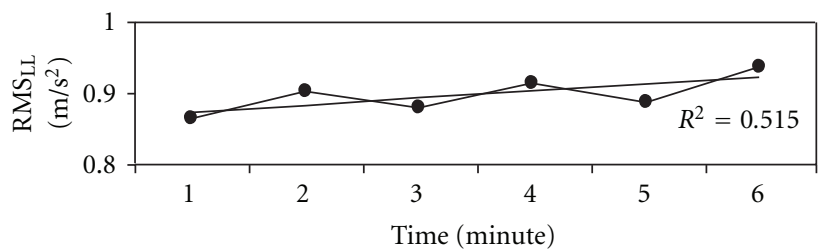

(c)

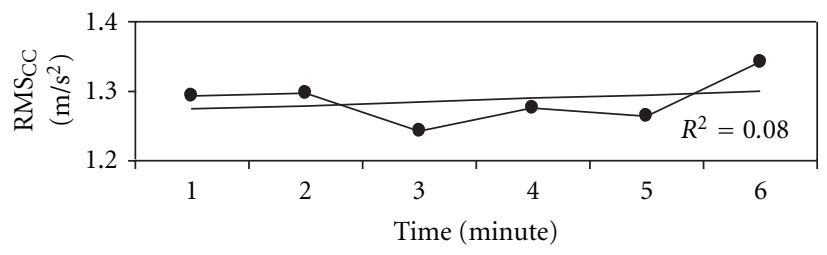

(e)

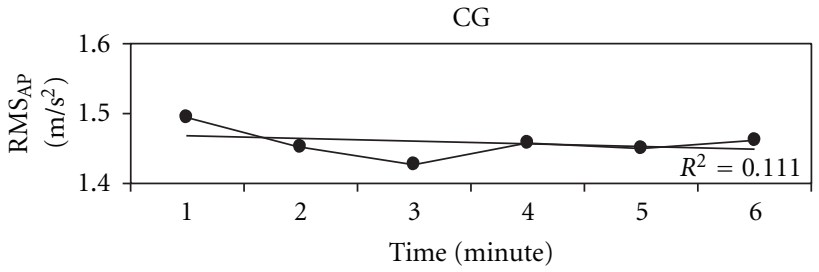

(b)

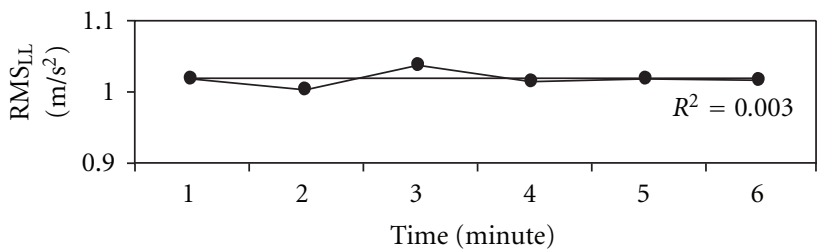

(d)

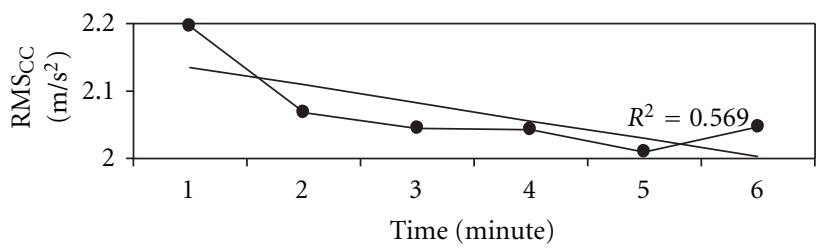

(f)

Figure 2: Acceleration RMS for PG1 ((a), (c), and (e)) and CG ((b), (d), and (f)) along anteroposterior ((a) and (b)), laterolateral ((c) and (d)) and craniocaudal ((e) and(f)) directions. Regression lines and relevant coefficient of determination $R^{2}$ are also reported.

accelerations have already been showed as the most informative for assessing the gait stability and also the most correlated with the risk of fall $[11,23]$. These findings seem to be consistent with the changes in kinematic [7] and kinetic [5] gait parameters already observed during 6MWT performed by people with stroke. Further studies on wider samples of patients should investigate whether this reduction of gait stability is progressive, as our results seem to show, or it happens only after an identifiable threshold. On the other hand, the reduction of walking speed probably used by some patients to compensate the reduction of gait stability could be anyway dangerous during outdoor walking. By way of example, an adequate gait velocity can be needed to perform some specific tasks, such as crossing the street during the green phase of traffic lights [24].

The main limitation of our study is the reduced size of healthy and patient samples especially in respect of the many features of stroke. Wider samples are needed in future studies to further explore the differences between patients who could and those who could not complete the 6-minute walking test. Another important aspect that needs to be further investigated is the stabilizing effect of the use of a cane or of the therapist's touch during walking. It should be noted that in our study the needs of external helps were similar in the two subgroups of patients (as shown by similar autonomy walking level: see values of FAC scores in Table 1), affecting the upper body accelerations in a similar manner. Finally, the difficulties encountered by participants turning at the end of each lap and the upper body accelerations during turning have been not taken into account in this study. Further researches should deeply investigate this aspect of walking component that can lead to differences in upper body accelerations. Despite these limitations, our study provided important information about the relationship between upper body dynamic stability and walking endurance.

Our results should be read in conjunction with those of Lerdal and colleagues in which it has been shown how an increased mobility may increase exposure to fall opportunities [3]. Walking speed, gait stability, and endurance should be hence quantitatively assessed and improved during rehabilitation in order to allow patients to walk in a functional and safe manner. Furthermore, accelerometry has been recently proposed for assessing the patients' performances during robotic gait training [25] and daily life activities [26]. The quantitative assessment of ability and stability of gait can improve the effectiveness of an intensive training designed around the actual patient's locomotor capacity [27] and the "locomotor awareness" of the patients about his/her abilities and limits.

\section{Conclusion}

Patients with stroke showed a reduction of walking speed and/or a reduction of gait stability during prolonged walking. In particular, the patients able to complete the six-minute walking test maintained a steady speed over the course of the walk, but their upper body accelerations progressively increased, exposing them to the risk of falling. 


\section{References}

[1] R. W. Teasell, S. K. Bhogal, N. C. Foley, and M. R. Speechley, "Gait retraining post stroke," Topics in Stroke Rehabilitation, vol. 10, no. 2, pp. 34-65, 2003.

[2] S. Paolucci, M. Bragoni, P. Coiro et al., "Quantification of the probability of reaching mobility independence at discharge from a rehabilitation hospital in nonwalking early ischemic stroke patients: a multivariate study," Cerebrovascular Diseases, vol. 26, no. 1, pp. 16-22, 2008.

[3] A. Lerdal, L. N. Bakken, S. E. Kouwenhoven et al., "Poststroke fatigue-A review," Journal of Pain and Symptom Management, vol. 38, no. 6, pp. 928-949, 2009.

[4] E. McGeough, A. Pollock, L. N. Smith et al., "Interventions for post-stroke fatigue," Cochrane Database of Systematic Reviews, no. 3, Article ID CD007030, 2009.

[5] S. J. Lewis, A. J. Barugh, C. A. Greig et al., "Is fatigue after stroke associated with physical deconditioning? A crosssectional study in ambulatory stroke survivors," Archives of Physical Medicine and Rehabilitation, vol. 92, no. 2, pp. 295298, 2011.

[6] L. A. Simpson, W. C. Miller, and J. J. Eng, "Effect of stroke on fall rate, location and predictors: a prospective comparison of older adults with and without stroke," PLoS One, vol. 6, no. 4, article e19431, 2011.

[7] K. M. Sibley, A. Tang, K. K. Patterson, D. Brooks, and W. E. McIlroy, "Changes in spatiotemporal gait variables over time during a test of functional capacity after stroke," Journal of NeuroEngineering and Rehabilitation, vol. 6, no. 1, article 27, 2009.

[8] S. Straudi, M. Manca, E. Aiello, G. Ferraresi, S. Cavazza, and N. Basaglia, "Sagittal plane kinematic analysis of the six-minute walk test: a classification of hemiplegic gait," European Journal of Physical and Rehabilitation Medicine, vol. 45, no. 3, pp. 341347, 2009.

[9] J. J. Kavanagh and H. B. Menz, "Accelerometry: a technique for quantifying movement patterns during walking," Gait and Posture, vol. 28, no. 1, pp. 1-15, 2008.

[10] C. Mazzà, M. Iosa, F. Pecoraro, and A. Cappozzo, "Control of the upper body accelerations in young and elderly women during level walking," Journal of NeuroEngineering and Rehabilitation, vol. 5, article 30, 2008.

[11] M. Iosa, C. Mazzà, F. Pecoraro, I. Aprile, E. Ricci, and A. Cappozzo, "Control of the upper body movements during level walking in patients with facioscapulohumeral dystrophy," Gait and Posture, vol. 31, no. 1, pp. 68-72, 2010.

[12] C. Mizuike, S. Ohgi, and S. Morita, "Analysis of stroke patient walking dynamics using a tri-axial accelerometer," Gait and Posture, vol. 30, no. 1, pp. 60-64, 2009.

[13] F. I. Mahoney and D. W. Barthel, "Functional evaluation: the Barthel index," Maryland State Medical Journal, vol. 14, pp. 61-65, 1965.

[14] M. K. Holden, K. M. Gill, and M. R. Magliozzi, "Gait assessment for neurologically impaired patients. Standards for outcome assessment," Physical Therapy, vol. 66, no. 10, pp. 1530-1539, 1986.

[15] C. M. Dean, C. L. Richards, and F. Malouin, "Walking speed over 10 metres overestimates locomotor capacity after stroke," Clinical Rehabilitation, vol. 15, no. 4, pp. 415-421, 2001.

[16] S. E. Lord and L. Rochester, "Measurement of community ambulation after stroke: current status and future developments," Stroke, vol. 36, no. 7, pp. 1457-1461, 2005.

[17] J. J. Eng, K. S. Chu, A. S. Dawson, C. M. Kim, and K. E. Hepburn, "Functional walk tests in individuals with stroke: relation to perceived exertion and myocardial exertion," Stroke, vol. 33, no. 3, pp. 756-761, 2002.

[18] B. H. Dobkin, "Short-distance walking speed and timed walking distance: redundant measures for clinical trials?" Neurology, vol. 66, no. 4, pp. 584-586, 2006.

[19] I. Bautmans, B. Jansen, B. Van Keymolen, and T. Mets, "Reliability and clinical correlates of 3D-accelerometry based gait analysis outcomes according to age and fall-risk," Gait and Posture, vol. 33, no. 3, pp. 366-372, 2011.

[20] A. Ramnemark, L. Nyberg, B. Borssén, T. Olsson, and Y. Gustafson, "Fractures after stroke," Osteoporosis International, vol. 8, no. 1, pp. 92-95, 1998.

[21] B. Vellas, F. Cayla, and H. Bocquet, "Prospective study of restriction of activity in old people after falls," Age and Ageing, vol. 16, no. 3, pp. 189-193, 1987.

[22] M. J. Pavol, T. M. Owings, K. T. Foley, and M. D. Grabiner, "Mechanisms leading to a fall from an induced trip in healthy older adults," The Journals of Gerontology-Series A, vol. 56, no. 7, pp. M428-M437, 2001.

[23] H. B. Menz, S. R. Lord, and R. C. Fitzpatrick, "Acceleration patterns of the head and pelvis when walking are associated with risk of falling in community-dwelling older people," The Journals of Gerontology-Series A, vol. 58, no. 5, pp. 446-452, 2003.

[24] S. Hesse, A. Welz, E. Assmann, B. Quentin, and A. Waldner, "Pedestrians in Berlin after stroke: recommendations for street and subway transit," Nervenarzt, vol. 80, no. 8, pp. 953-958, 2009.

[25] M. Iosa, G. Morone, M. Bragoni et al., "Driving electromechanically assisted gait trainer for people with stroke," Journal of Rehabilitation Research and Development, vol. 48, no. 2, pp. 135-146, 2011.

[26] B. H. Dobkin, X. Xu, M. Batalin, S. Thomas, and W. Kaiser, "Reliability and validity of bilateral ankle accelerometer algorithms for activity recognition and walking speed after stroke," Stroke A Journal of Cerebral Circulation, vol. 42, no. 8, pp. 2246-2250, 2011.

[27] G. Morone, M. Bragoni, M. Iosa et al., "Who may benefit from robotic-assisted gait training? A randomized clinical trial in patients with subacute stroke," Neurorehabilation and Neural Repair, vol. 25, no. 7, pp. 636-644, 2011. 


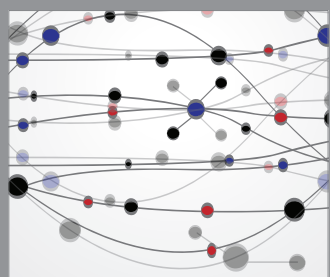

The Scientific World Journal
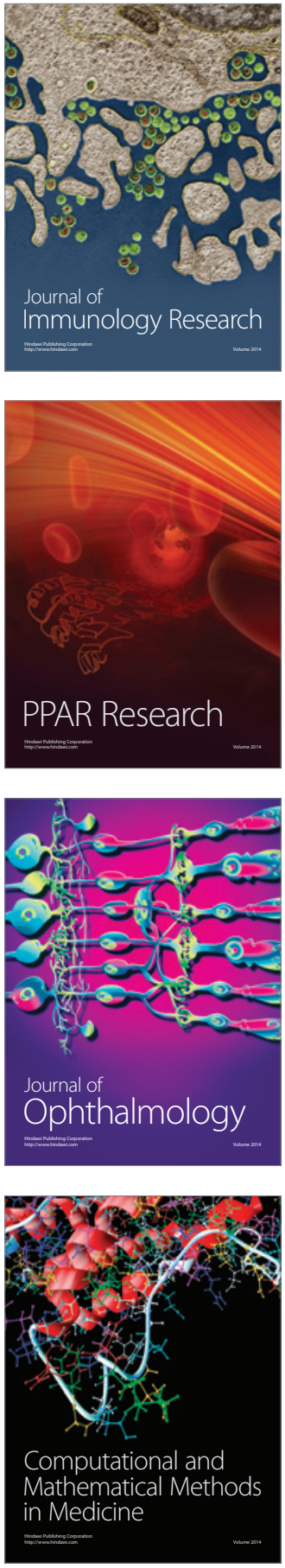

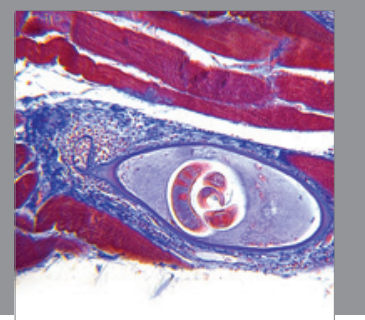

Gastroenterology

Research and Practice
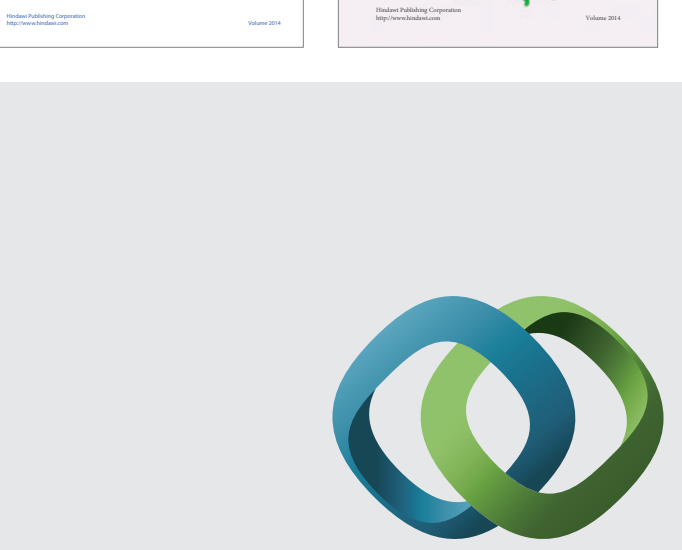

\section{Hindawi}

Submit your manuscripts at

http://www.hindawi.com
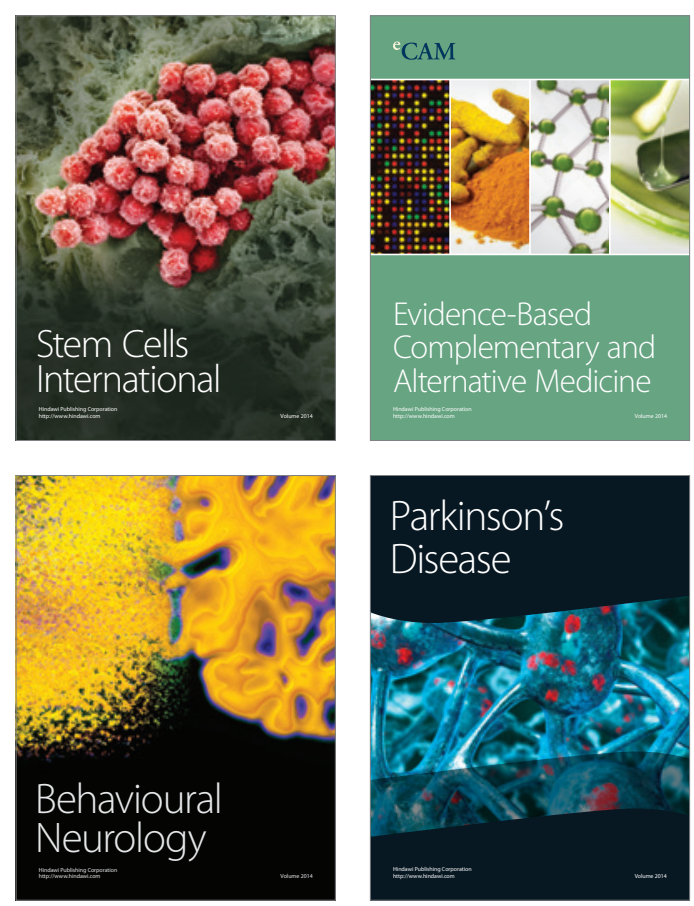

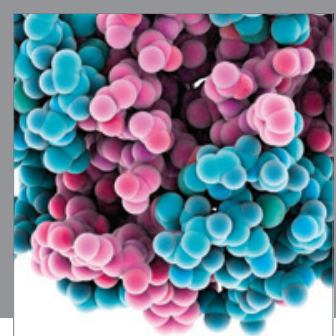

Journal of
Diabetes Research

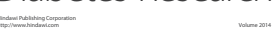

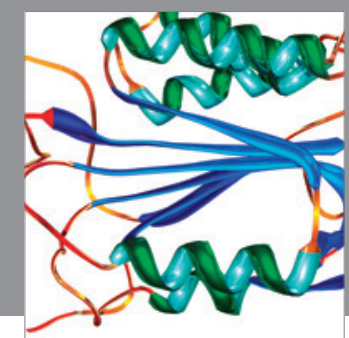

Disease Markers
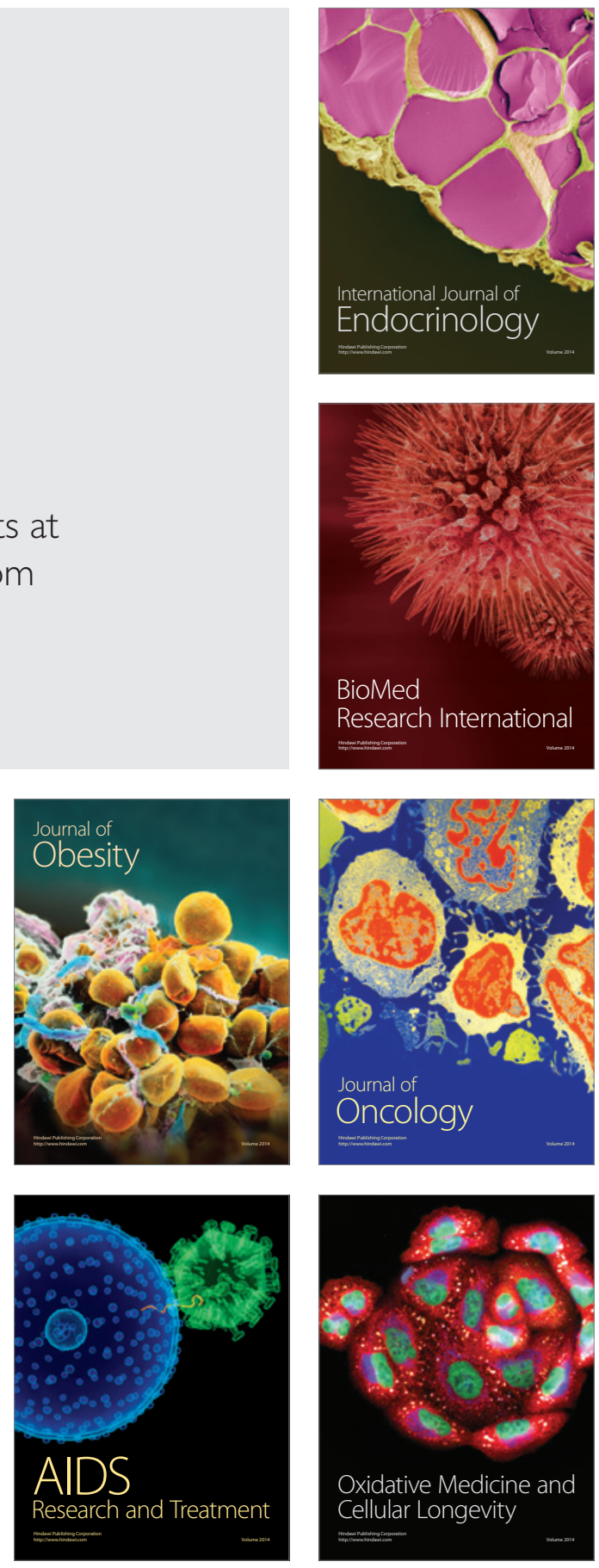